\title{
Suffering Exhausted Life Like Burning at Both Ends of a Candle - Women With Menopausal Fatigue
}

\author{
Hsiao-Hui Chiu ${ }^{1}$, lee-Ing $\mathrm{Tsao}^{2} \&$ Mei-Hsiang $\mathrm{Lin}^{2}$ \\ ${ }^{1}$ Taipei Veterans General Hospital, Department of Nursing, National Taipei University of Nursing and Health \\ Sciences, Taipei, Taiwan \\ ${ }^{2}$ Department of Nursing, National Taipei University of Nursing and Health Sciences, Taipei, Taiwan \\ Correspondence: Hsiao-Hui Chiu, Doctoral Candidate, Nurse Supervisor, Department of Nursing, National Taipei \\ University of Nursing and Health Sciences, Taipei Veterans General Hospital, Taipei, Taiwan.
}

Received: March 10, 2020

Accepted: March 20, 2020

Online Published: March 30, 2020

doi:10.20849/ijsn.v5i1.722

URL: https://doi.org/10.20849/ijsn.v5i1.722

\begin{abstract}
Background: Fatigue is a common complaints for perimenopausal or menopausal women. It is a subjective feeling and deeply affect women's lives. Studies evaluating it as a marker for diseases or the transition of menopause among menopausal women are lacking.
\end{abstract}

Aims: To explore the life experiences among women with menopausal fatigue.

Methods: In- depth interview were conducted with 17 Taiwanese women with a mean age of 52.2years, who perceived themselves as getting tired or exhausted life but have no major or serious diseases were invited by in-depth interviewed. Data were analyzed by constant comparative method.

Results: "Suffering exhausted life like burning at both ends of a candle" was the core category for describing and guiding the process of women with menopausal fatigue. During this process, "Energy Exhaustion" was identified as the antecedent condition. Once the woman became aware, she would begin the process of "Suffering exhausted life like burning at both ends of a candle". This process would be marked by action and interaction among the categories of "Need refreshing or diverting attention", "Seeking family or significance others help and supports", and "Arranging leisure activities and exercise". Throughout this process women viewed their fatigue life by acceptance by "Slowing and modifying my life paces" or retrieval it but felt frustration and recycling the process of Energy Exhaustion.

Conclusion: Menopausal fatigue was viewed as suffering exhausted life like burning at both ends of a candle instead of a silent life message. It is like menopausal symptoms needing to attention.

Keywords: grounded theory, menopausal fatigue, menopause, women health

\section{Introduction}

Menopausal fatigue involves a feeling of completely lacking of energy, the symptom is characterized by the sensation of insufficient capacity in proceeding the activities previously conducted, being not necessarily tired or feeling sleepy. The average age of menopause was $49 \pm 4$ years old and the average menopause age of Taiwanese women is from 45 to 52 years old (The Taiwanese menopause society, 2017).A hormonal imbalance can cause menopausal fatigue, the fluctuated and decreased level of estrogen may lead to feeling of fatigue; the altered hormone levels develop disruption on normal sleep pattern, resulting in daytime fatigue (MenoMe, 2018). Menopausal fatigue affects women's day-to-date activities, tiredness and a lack of energy are common complaints of daily life in menopausal women which even leads to seeking medical attention. Menopausal fatigue is a unique, complicated and multidimensional subjective experience, which is not exactly the same as fatigue related to an underlying illness but closely associated with healthy and comfortable life during menopause. Nevertheless, there are only few studies investigating this issue. The study aims to closely investigate the subjective experiences and life course in women suffering from menopausal fatigue, providing references for more comprehensive physical and psychological health during menopause.

Fatigue is a globally popular symptom with defining characteristics frequently confounded with depression or anxiety. Most physical and mental illnesses have a problem of fatigue, fatigue is experienced as an internal and 
subjective unpleasant feeling that influences physiological and psychological status with declined activity and motivation (Ream \& Richardson, 1996).

During menopause many women may experience an ongoing and persistent lack of vitality and feelings of tiredness and weakness. They normally feel exhausted with unexplainable status. The signs of menopausal fatigue include decreased wakefulness, lowered attention span, mental fuzziness, irritability, memory lapses, and a lack of usual zest for life. The main cause of menopausal fatigue is the change in hormone levels. Estrogen, progesterone, thyroid and adrenal hormones are all involved in regulating cellular energy in the body which when compromised can lead to fatigue. Menopausal symptoms such as night sweats and insomnia contribute to fatigue. Many women find themselves experiencing chronic sleep deprivation and this is a contributory factor to daytime fatigue. Fatigue exacerbates menopausal symptoms such as anxiety, poor concentration, and a lack of confidence, which can easily lead to a spiraling, vicious circle (My Second Spring, 2018). Hall et al. (Hall, Leach, \& Kynerd, 2005) suggest that menopause is a natural transition in a woman's life, hormonal changes can lead to hot flashes, night sweats, vaginal dryness and urinary tract symptoms. The frequent complaint of fatigue, after the exclusion for a cause of illness such as thyroid or cardiovascular disease, is suspected fatigue caused by the decreased hormone levels in menopause. With the measures using physical examination and medical history inquiry, 448 middle-aged women were included in the investigation for their frequent episodes of menopausal symptoms, the result found that feelings of "tiredness" (89\%) and "a lack of energy" (83\%) were the mostly frequent complaints in symptoms of fatigue. Durward (2018) suggests the causes of fatigue in menopausal women include physical status in menopause, emotions, improper diet, insufficient or excessive exercise, etc. Most studies viewed menopausal fatigue as related with menopausal symptoms instead of a comprehensive concept. Studies evaluating it as a marker for diseases or the transition of menopause among menopausal women are lacking. Most studies viewed menopausal fatigue as related with menopausal symptoms instead of a comprehensive concept. Studies evaluating it as a marker for diseases or the transition of menopause among menopausal women are lacking.

\section{Method}

\subsection{Research Design}

This study applied grounded theory methodology using symbolic interaction theory as the framework. Grounded theory involves a methodology developed for descriptive generalizations based on qualitative research which primarily conducts research on a specific phenomenon that describes certain experience of individuals but no any theory has explained such an experience. Procedures of the research stresses capturing subjective experience of the respondents to understand the course in people with such a specific experience, involving the description on association between context, process, meaning and action. The research procedure involves systematic collection of qualitative data and related analysis, repeated verification and collection are conducted throughout the data analysis before progressively achieves theoretical saturation without any new analytical categories identified, the theory is then developed.

\subsection{Participants}

Target population of this study involved women in a medical center and community experienced natural menopause between ages 42 and 58, recruitment criteria included (1) women between ages 42 and 58; (2) women in menopause with non-disease-related fatigue for more than one month - those who seek medical attention at obstetrics and gynecology clinic due to menopausal symptoms or community women; (3) able to communicate in Mandarin or Taiwanese; (4) excluded for patients with critical illness, cancer or mental illness, being chronically bedridden, or menopause resulted from bilateral oophorectomy; (5) those who are with normal cognitive function, able to answer questions and sign an informed consent.

The study used purposive sampling as a sampling technique, subjects able to provide the researcher with relevant information to achieve purpose of the study were carefully selected from accessible population, increasing class attribute and dimensional saturation (Strauss, 1990). The sample size used in this study was determined by data saturation, referring to the point in the data analysis when no any new categories is concluded by use of information provided by any new sample, the inclusion was ended right after the number of individual samples reached categorical saturation.

\subsection{Data Collection}

The study was conducted between April and May 2019. Before enrollment of the study, 3 cases were interviewed and the wording in the interview outline was modified after the interview completed to make the questions clearer and more easily understandable. The researcher is a female herself acting as one of the research tools, 
presently serving as the Chief Nursing Supervisor for outpatient department of a medical center, acquiring 6 years of clinical nursing experience in obstetrics and gynecology. With the present status as a $\mathrm{PhD}$ candidate in nursing, the researcher has received a 3-credit learning course in qualitative research. The researcher personally fulfilled the duties as an interviewer, data translator and text analyst in data collection.

Before performing the interview, purpose of the study and interview procedure were explained. After the respondent agreed and the informed consent obtained, consulting room of the medical center was selected as an isolated and private setting to arrange face-to-face interview. Recording equipment was used throughout the interview to record the interview content, duration of the interview was about $30 \mathrm{~min}$. After end of the interview, the record information was verbatim written into text information using Microsoft Word. Enrollment of this study was performed after the study was reviewed and approved by the Institutional Review Board of Taipei Veterans General Hospital (IRB No: 2019-02-006AC)

\subsection{Data Analysis}

Grounded theory argues that data collection and data analysis are performed simultaneously and the following data collection is guided by the result of data analysis. The data collected were coded, classified and conceptualized using constant comparative analysis to persistently circulating the abovementioned process until the point of data saturation (Strauss, 1990). In this study, the recorded content of each interview was immediately written into text record after end of the interview. The researcher and a senior nursing research expert were immersed in the original data, carefully examining the transcript to each line, sentence, and paragraph. The data were conceptualized after coding, similar conceptions were classified in the same category, with the data increased, categories were continuously clarified, amended, progressively forming the core category. The process of data analysis consisted of persistent collection, comparison and thought of the data, the abovementioned procedure was repeated upon discrepancy between various viewpoints on clarification.

\subsection{Rigorousness}

Rigour involves four criteria including (1) truth value, (2) applicability, (3) consistency, and (4) neutrality, which are used to perform judgement on rigour of the research (Lincoln \& Guba, 1994). In true value, the researcher was simultaneously present in the physician's clinic, the trust relationship between the researcher and participant was enhanced through the physician's introduction. For cases conformed to inclusion criteria, agreement of the case to participate the study was obtained. With the open-ended interview guide through in-depth interview, the participants were able to freely describe their subjective experience. During the interview, all expected content and feelings from respondents were confirmed, the enthusiastic participants were asked to reconfirm if result of data analysis represented their real-life experience. In applicability, this qualitative research involved description of experience and feelings, the research result was analyzed and concluded mutually by the researcher and the qualitative research expert; moreover, the definite inclusion criteria established by the researcher for selection of respondents was also beneficial for data saturation. In consistency, the researcher invited a PhD qualitative researcher with professor qualification whom possesses extensive analytical experience in qualitative research. The interview process was reverified, repeated analysis, verification, induction and categorization were persistently conducted by the researcher throughout the study to fulfill the stability for study result. Data of the entire study were securely reserved (including use of recording equipment) to establish clues for investigation, enhancing reliability. In neutrality, in addition to the faithful presentation of interview content from the respondents using recording equipment by the researcher in the study, the recording of interview content and text analysis were also completely reserved as important reference for further investigation. Moreover, comparison of classification in data documentation and categorization were persistently performed throughout the data analysis for establishing objectivity and scientificity of the data analyzed.

\section{Results}

\subsection{Sample Characteristics}

A total of 17 cases were interviewed, an analysis for 17 menopausal women was performed without any case rejected, one interview was performed for each case, mean age was 52.2 years, $76.5 \%$ with a job, $88.2 \%$ were married, $52.0 \%$ in menopause, $52.9 \%$ with 2 childbirths. Demographic information is shown as Table 1.

Table 1. Demographic information

\begin{tabular}{|c|c|c|c|c|}
\hline Age (years) & $\begin{array}{l}\text { Educational } \\
\text { Background }\end{array}$ & Job Status & $\begin{array}{l}\text { Marital } \\
\text { Status }\end{array}$ & $\begin{array}{l}\text { Menstrual } \\
\text { Status }\end{array}$ \\
\hline
\end{tabular}




\begin{tabular}{|c|c|c|c|c|c|}
\hline 52 & Master & Yes & Married & Unstable & 2 \\
\hline 55 & University & Yes & Married & Unstable & 2 \\
\hline 46 & Master & No & Married & Unstable & 2 \\
\hline 52 & Master & Yes & Married & Menopause & 2 \\
\hline 55 & University & Yes & Married & Menopause & 0 \\
\hline 46 & $\begin{array}{l}\text { Vocational } \\
\text { high school }\end{array}$ & Yes & Married & Menopause & 3 \\
\hline 50 & $\begin{array}{l}\text { Junior } \\
\text { college }\end{array}$ & Yes & Married & Unstable & 1 \\
\hline 57 & University & Yes & Married & Menopause & 1 \\
\hline 55 & $\begin{array}{l}\text { Vocational } \\
\text { high school }\end{array}$ & No & Married & Menopause & 3 \\
\hline 51 & Master & Yes & Married & Unstable & 2 \\
\hline 55 & University & Yes & Married & Menopause & 2 \\
\hline 51 & $\begin{array}{l}\text { Vocational } \\
\text { high school }\end{array}$ & Yes & Married & Unstable & 2 \\
\hline 42 & Master & Yes & Divorced & Unstable & 2 \\
\hline 58 & $\begin{array}{l}\text { Vocational } \\
\text { high school }\end{array}$ & Yes & Married & Menopause & 2 \\
\hline 56 & $\begin{array}{l}\text { Commercial } \\
\text { high school }\end{array}$ & No & Married & Menopause & 3 \\
\hline 52 & $\begin{array}{l}\text { Junior high } \\
\text { school }\end{array}$ & No & Married & Unstable & 3 \\
\hline 55 & University & Yes & Single & Menopause & 0 \\
\hline
\end{tabular}

\subsection{Core Category}

"Suffering exhausted life like burning at both ends of a candle" (Figure 1) was found to be the core category in this study, the theoretical framework is shown as Figure 1. Fatigue is a subjective feeling of declined energy and exhaustion, which can be alleviated by refreshing. It is required to seek support and assistance from family or significant others, seeking medical attention from healthcare resources including traditional Chinese medicine, western medicine, complementary and alternative medicine (CAM) or psychological counseling, as well as arranging leisure activities or exercises. After such a course, the life paces are to be slowed and modified upon acceptance, in case of retrieval, feelings of frustration can occur, including helplessness, self-anger, and self-enclosedness.

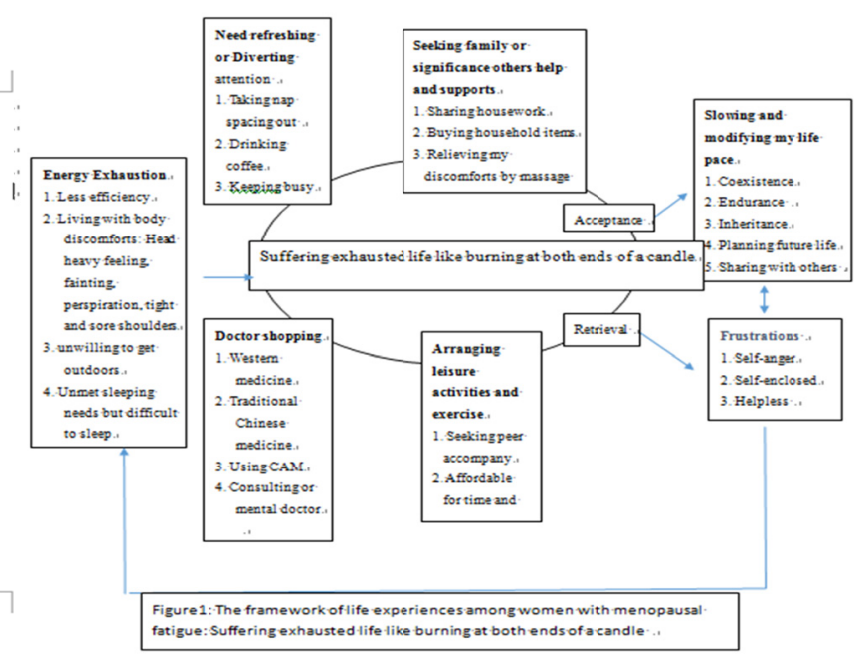




\subsubsection{Energy Exhaustion}

It refers to a lack of energy: feeling extremely tired, with feeling of sleep deprivation. Associated conditions include: (1) Less efficiency. (2) Living with body discomforts such as headache, tiredness, sweating, neck/shoulder soreness and tightness. (3) Unwillingness to get outdoors. (4) Unmet sleeping needs with difficulty in falling asleep.

For example, one woman said:

It's tiredness! Always feel tired, fatigue is quite a problem too. It always caused feeling upset, feeling unsettled and short-tempered, which also resulted from fatigue. Accuracy has been no longer strictly required in doing something, I become turning a blind eye to what has been done wrong, having no intention of doing anything else. (Case 2)

Another woman said:

The problem is always feeling very tired after getting up in the morning, feeling painful in all joints...It's tiredness, the feeling like even unable to move. I really want to walk but unable to step out which is such tiredness with weakness and sometimes I even can't sleep well at night...I have impaired quality of sleep sometimes with dreamy sleep just like electronic scroll signs, I can even remember what the dreams were. So sometimes I feel even more tired after getting up, experiencing severer tiredness in the morning probably due to the impaired quality of sleep. (Case 17)

\subsubsection{Need Refreshing or Diverting Attention}

It refers to failure to inherit or defer workload, feeling of requiring some measures to restore the spirit. It involves the perceived needs in spacing out, drinking coffee, and keeping oneself busy.

For example, one woman said:

In such a condition, I always do something fluffy, doing boring things such as shopping or going to the movies, spacing out for a bit comfort. I've arranged some more time for shopping as daily activity this year, otherwise I'll become insane, really, ha-ha! (Case 2)

Another woman said:

I always drink coffee to hold. When I feel very tired, I drink coffee right after getting up in the morning which makes me feel vigorous with reduced tiredness. (Case 6)

\subsubsection{Doctor Shopping: Seeking Healthcare Resources}

It refers to requiring to seek medical attention from healthcare resources for the perceived physical or psychological symptoms, including traditional Chinese medicine, western medicine, CAM or psychological counseling.

For example, one woman said:

I visited department of Allergy, Rheumatology and Immunology when I experienced joint pain, worrying about if I've suffered from ankylosing spondylitis. I experienced difficulty in exerting the knees when walking upstairs. Moreover, mild osteoporosis was also found after visiting the OPD. (Case 1)

Another woman said:

Well, the Chinese medicine practitioner immediately told me that I experienced insufficiency of qi and blood with cerebral hypoxia resulted from the impaired blood circulation to the brain, that's all what he said about signs of the forthcoming menopause. He said I'd better get ready to experience menstrual disturbance, first helping me to regulate menstruation then, which's sort of treatment because I also took isoflavone capsules. The period came right after I took the medication. I asked the doctor later about the safety of such a plant-derived hormone. I was a bit worried after doing some research on related information. (Case 3)

\subsubsection{Seeking Family or Significance Others Help and Supports}

It refers to seek assistance from family in sharing housework, buying household items, and relieving the discomfort by measures such as body massage.

For example, one woman said:

I can endure all these discomforts only if my husband likes to inherit my further uncomfortable symptoms of the body for me to avoid doing such heavy housework.

Another woman said: 
My children are pretty okay, I always told them clearly when their mom was very tired. ...They'd come to massage for me showing consideration sometimes when I felt body aches. (Case 3)

\subsubsection{Arranging Leisure Activities and Exercise}

It refers to seek assistance from family in sharing housework, buying household items, and relieving the discomfort by measures such as body massage.

For example, one woman said:

I can endure all these discomforts only if my husband likes to inherit my further uncomfortable symptoms of the body for me to avoid doing such heavy housework. (Case 2)

Another woman said:

My children are pretty okay, I always told them clearly when their mom was very tired. ...They'd come to massage for me showing consideration sometimes when I felt body aches. (Case 3)

\subsubsection{Slowing and Modifying My Life Pace}

It refers to harmony with, face, endure or share with others the physical or mental fatigue or discomfort for slowing or modifying life pace and planning for future life, including coexistence with symptoms or discomfort, endurance, inheritance, planning for future life and sharing with others.

For example, one woman said:

Something like avoiding to be demanding of myself in increase of my stress, I know that it's required to adapt to the present conditions, shouldn't walk fast or be in a hurry as before. Contrarily, it's necessary to understand and accept my own situations now, accepting progressively entering another stage. (Case 2)

Another woman said:

I'd say it's peaceful coexistence, all these conditions are unchangeable, so I mostly find out some ways to solve it by myself, proceeding to peaceful coexistence. (Case 5)

\subsubsection{Frustrations}

It refers to possible feelings of frustration resulted from failure to manage the fatigue sensation, including helplessness, self-anger, and self-enclosedness.

For example, one woman said:

Because my husband and children are much demanding of me, I've always pulled myself together and did what's to be done. After I finished it, I felt okay because after all I've done so many things even though I was that tired. Therefore, sometimes I'd encourage myself by recalling what's been done when I was really tired, and even went to do exercises which made me feel not so bad and seemed endurable, so I'd keep trying to put up with all these conditions. I'd keep telling myself this way. (Case 3)

Another woman said:

It seems like that I've experienced depression, sometimes I felt very sad and the tears voluntarily fell. ... On several occasions when I came close to the lotus pond, I'd want to jump in because I just felt so sad.... (Case 6)

\section{Discussion}

In summarizing the data analysis for case interview, this study found that menopausal fatigue is "a subjective feeling of declined energy and exhaustion" which is consistent with "fatigue is experienced as an internal and subjective unpleasant feeling that influences physiological and psychological status with reduced activity and motivation" found by Ream et al. (Ream \& Richardson, 1996). Moreover, Genneve (2018) suggests that menopausal fatigue is more than "tiredness", it is even worse than "exhaustion", in fact, which involves "because of tiredness, I'm not sure if or not I can get up today", rather than "because I'm tired, I don't want to do exercises today". On the other hand, Aaronson et al. (1999) indicates "fatigue is a subjective feeling involving physical, cognitive, and emotional dimensions with painful and unpleasant experience. An unendurable feeling of exhaustion is still experienced even got plenty of rest, with declined physical capability and mental ability too." Hall et al (2005) suggest that feeling of "tiredness" (89\%) and "a lack of energy" (83\%) are the most frequent complaints in fatigue symptoms, which is consistent with the result of this study. Menopause or menopausal fatigue is an unidentified illness indicator and can be a transition of menopause. Nevertheless, because there have been few studies in this domain, more empirical research is warranted, conducting overall further investigation for more accurate management in health issue of menopausal fatigue. Studies found that menopausal women experienced necessity for rest and refreshing in their daily life. It is indicated that many 
women found themselves suffering from chronic sleep deprivation and this is a contributory factor to daytime fatigue. Fatigue exacerbates menopausal symptoms (Durward, 2018; My Second Spring, April 2018).

Result of this study found that feelings of frustration can occur in case of failure in adaptation, including helplessness, self-anger, and self-enclosedness, which is consistent with the result found by scholar Cahill (1999) suggesting that physiological fatigue frequently coexists with major depression. This study found that menopausal women experienced fatigue may "seek support and assistance from family or significant others", "seek medical attention from healthcare resources" or "arrange leisure activities or exercises". Yancey et al. (2012) suggest that measures to manage chronic fatigue include: encouraging timely rest, practice of relaxation techniques, cognitive behavior therapy and exercises. The five measures to relieve fatigue proposed by Marcin (2017) include making time for regular exercise, developing a good sleep routine, taking a meditation break, turning down the thermostat at night and understanding perimenopause and menopause, which is similar to result of this study.

How to help with terminate recycling the life process of Energy Exhaustion is important issues. Menopausal fatigue refers to a lack of energy or exhaustion experienced by women, which can have physiological or psychological impact. Those who are with severe symptom may develop helplessness or even the intention of self-enclosedness, but successful adaptation can lead to positively planning for future life. Nevertheless, the sensation of fatigue is frequently neglected due to the influence from other uncomfortable symptoms in menopause. This study investigated the subjective experience of fatigue in menopausal women using qualitative research methodology to enhance the cognition of healthcare personnel on fatigue in menopausal women, allowing to positively providing health education guidance, assisting women to face the symptoms and accept the impact caused by menopause, successfully passing through menopause with the changed lifestyle and positively seeking support.

\section{Conclusion}

This study performed analysis on fatigue experience in 17 cases of menopausal women using grounded theory methodology, the core category was found as "Suffering exhausted life like burning at both ends of a candle". Energy consumption is the subjective experience of fatigue. Seeking healthcare resources is used to identify the health status, measures for adaptation include relieving fatigue through refreshing, arranging leisure activities or exercises. Daily housework shared by family, or sharing with and support from significant others can be the measure of adaptation in the cases for preventing fatigue from aggravation. With such regulating procedures, accepted cases can adapt and are capable of planning for future life, in case of failure in adaptation, feelings of frustration can occur. Fatigue experienced by menopausal women is not a silent message in their lives, healthcare providers should remain alert to middle-aged women with subjective complaint of fatigue, identifying the hidden impacts in their peaceful lives to help them face up to the change process in life. Takeing home message the relieve fatigue methods include making time for regular exercise, developing a good sleep routine, taking a meditation break, turning down the thermostat at night and understanding perimenopause and menopause.

\section{Study Limitation and Recommendation}

Limitation of this study is the research subjects involving small-size sample of women in northern area of Taiwan, expanded sampling area and size for future research are suggested. Menopausal fatigue was viewed as suffering exhausted life like burning at both ends of a candle instead of a silent life message. It is like menopausal symptoms needing to attention.

\section{Acknowledgements}

Collate acknowledgements in a separate section at the end of the article before the references. List here those individuals who provided help during the research (e.g., providing language help, writing assistance or proof reading the article, etc.). This research was by an intramural grant of Taipei Verterans General Hospital (V109A-029).

The funders had no role in the design of the study; in the collection, analysis, or interpreation of data; in the writing of the manuscript, or in the decision to publish the results.

\section{References}

American Psychological Association. (1972). Ethical standards of psychologists. Washington, DC: American Psychological Association.

Anderson, C. A., Gentile, D. A., \& Buckley, K. E. (2007). Violent video game effects on children and adolescents: Theory, research and public policy. https://doi.org/10.1093/acprof:oso/9780195309836.001.0001 
Beck, C. A. J., \& Sales, B. D. (2001). Family mediation: Facts, myths, and future prospects. Washington, DC: American Psychological Association. https://doi.org/10.1037/10401-000

Bernstein, T. M. (1965). The careful writer: A modern guide to English usage (2nd ed.). New York, NY: Atheneum.

Bjork, R. A. (1989). Retrieval inhibition as an adaptive mechanism in human memory. In H. L. Roediger III, \& F. I. M. Craik (Eds.), Varieties of memory \& consciousness (pp. 309-330). Hillsdale, NJ: Erlbaum.

Cress, C. M. (2009). Curricular strategies for student success and engaged learning [PowerPoint slides]. Retrieved from http://www.vtcampuscompact.org/2009/TCL_post/presenter_powerpoints/Christine\%20Cress\%20-\%20Curr icular\%20Strategies.ppt

Driedger, S. D. (1998, April 20). After divorce. Maclean's, 111(16), 38-43.

Gibbs, J. T., \& Huang, L. N. (1991). Children of color: Psychological interventions with minority youth. San Francisco, CA: Jossey-Bass.

Gilbert, D. G., McClernon, J. F., Rabinovich, N. E., Sugai, C., Plath, L. C., Asgaard, G., ... Botros, N. (2004). Effects of quitting smoking on EEG activation and attention last for more than 31 days and are more severe with stress, dependence, DRD2 A 1 allele, and depressive traits. Nicotine and Tobacco Research, 6, 249-267. https://doi.org/10.1 080/1462220041 0001676305

Goleman, D. (2009). What makes a leader?. In D. Demers (Ed.), AHSC 230: Interpersonal communication and relationships (pp. 47-56) (Reprinted from Harvard Business Review, 76(6), pp.93-102, 1998). Montreal, Canada: Concordia University Bookstore.

Guignon, C. B. (1998). Existentialism. In E. Craig (Ed.), Routledge encyclopedia of philosophy (Vol. 3, pp. 493-502). London, England: Routledge.

Klimoski, R., \& Palmer, S. (1993). The ADA and the hiring process in organizations. Consulting Psychology Journal: Practice and Research, 45(2), 10-36. https://doi.org/10.1037/1061-4087.45.2.10

Kubrick, S. (1980). The Shining [Motion picture]. United States: Warner Brothers.

MacIntyre, L. (2002, January 23). Scandal of the Century [Television series episode]. In H. Cashore (Ed.), The fifth estate. Toronto, Canada: Canadian Broadcasting Corporation.

McLuhan, M. (1970a). Culture is our business. New York, NY: McGraw-Hill.

McLuhan, M. (1970b). From cliche to archetype. New York, NY: Viking Press.

Mellers, B. A. (2000). Choice and the relative pleasure of consequences. Psychological Bulletin, 126, 910-924. https://doi.org/10.1037/0033-2909.126.6.910

Postman, N. (1979). Teaching as a conserving activity. New York, NY: Delacorte Press.

Postman, N. (1985). Amusing ourselves to death: Public discourse in the age of show business. New York, NY: Viking.

Semenak, S. (1995, December 28). Feeling right at home: Government residence eschews traditional rules. Montreal Gazette, 4.

The Taiwanese menopause society. (2017). Health management and drug treatment recommendations for menopause women in Taiwan. from file:///C:/Users/user/Downloads/2013\%20\%E5\%8F\%B0\%E7\%81\%A3\%E6\%9B\%B4\%E5\%B9\%B4\%E6\% 9C\%9F\%E5\%A9\%A6\%E5\%A5\%B3\%E5\%81\%A5\%E5\%BA\%B7\%E7\%AE\%A1\%E7\%90\%86\%E5\%8F \%8A\%E8\%97\%A5\%E7\%89\%A9\%E6\%B2\%BB\%E7\%99\%82\%E6\%8C\%87\%E5\%BC\%95\%20(2).pdf

\section{Copyrights}

Copyright for this article is retained by the author(s), with first publication rights granted to the journal.

This is an open-access article distributed under the terms and conditions of the Creative Commons Attribution license (http://creativecommons.org/licenses/by/4.0/). 